\title{
Characteristic Features of Nanoscale Carbide Inclusions Nucleation and Growth When Carburizing Steels
}

\author{
L.I. Roslyakova ${ }^{1}$, I.N. Roslyakov,, , A.G. Besedin ${ }^{1}$
}

\section{Southwest State University, Department of General and Applied Physics, 94, 50 Let Oktyabrya st., 305040 Kursk, Russia \\ ${ }^{2}$ Kursk Academy of State and Municipal Service, Department of Information and Technosphere Safety, 9, Stantsionnaya st., 305040 Kursk, Russia}

(Received 08 May 2016; published online 03 October 2016)

\begin{abstract}
Thermodynamic calculations of the free energy of the formation of cementite type nanoscale carbides in supersaturated austenite alloyed with chromium and manganese are presented. It is shown that when carburizing steel, chromium stabilizing cementite facilitates its separation, in the form of dispersed inclusions. Manganese stabilizes cementite much weaker than chromium, though facilitates the growth of carbide inclusions due to the formation of the intermediate $\varepsilon$-phase at a reduced carbon content.
\end{abstract}

Keywords: Nanostructure-based processes, Carburization, Steel, Carbide inclusions.

DOI: $10.21272 /$ jnep.8(3).03010

PACS number: 77.84.Bw

\section{INTRODUCTION}

Cementation of chromium-manganese steels in highly active carburizing material can lead to the diffusion layers saturation with plenty of solid dispersed inclusions, which are carbides of a cementite type. After quenching and low tempering, a part with surface carbidecontaining layers acquire extremely high abrasive wear resistance [1].

Anisotropy and heterogeneity of physical and mechanical properties are common to cementite which confirms the complex character of interatomic bonding. In steel cementite presents a metastable phase and an alloying elements, which do not form carbides ( $\mathrm{Si}, \mathrm{Ni}$ etc.), and facilitate graphitization. The influence of carbideforming elements on the stability of cement depends on the solubility of these elements in it. Carbide-forming elements, which are to the left and below chromium in the Mendeleev periodic system, do not stabilize cementite and facilitate carbon transition into special carbides.

The use of highly activate carburizing materials delivering sufficient amount of carbon for carbide inclusions formation and growth, as well as alloying of carburizing steels with carbide-forming elements such as chromium and manganese for carburizing facilitate the formation of the excess cementite phase in the diffusion layers of structural steels. These elements dissolving in cementite in large amounts (chromium - up to $20 \%$, manganese - unlimited) stabilize it, and should facilitate the formation of the mentioned carbide in austenite during the intensive carburization of the last.

The difference of free energies of austenite and cementite is the driving force that causes the formation of cementite during steel carburization at cementation temperature. It is known that the alloying elements, which present in steel, have a significant effect on the thermodynamic properties of the phases [2]. This is the reason why it is interesting to analyze the dependence of the free energy of the formation of austenite and cementite in the most widely used chromium and manganese steels.

\section{RESEARCH OBJECT AND TECHNIQUES}

Nanostructure-based processes occurring on the surface of carburizing steel during its carburization are the object of the study. Thermodynamic calculation is the research method.

\section{RESULTS DESCRIPTION AND ANALYSIS}

Cementite has an orthorhombic lattice with such parameters as $a=4,5144 \AA, b=5,078 \AA$ and $a=6,7287 \AA$. The arrangement of carbon and ferrum atoms in cementite lattice, as well as the nature of its interatomic bindings has not been determined exactly yet. According to the most widely spread opinion, the carbon is in the octahedral interstices of the cementite ferrum sub-lattice (as well as in austenite), the interatomic binding has integrated covalent-metal character, moreover, covalent binding is the dominant one.

The concentration dependence of the free energy of austenite formation and free energy of cementite formation in $\mathrm{Fe}-\mathrm{Me}-\mathrm{C}$ systems, where $\mathrm{Me}$ is chromium or manganese, was calculated according to the equations [3]:

$$
\begin{aligned}
& \Delta G_{\gamma}^{0}=R T\left[N_{c^{\prime}} \ln a_{c^{\prime}}+N_{{ }_{M}}^{\prime} \ln a^{\prime}+N_{{ }_{M}}^{\prime} \ln a_{{ }_{M}}^{\prime}\right. \\
& \left.+\left(l-N_{c^{\prime}}-N^{\prime}{ }_{M}\right) \ln a^{\prime} \mathrm{Fe}\right] \\
& \Delta G^{0}{ }_{M e 3 C}=1 / 4 R T\left[\ln \mathrm{a}{ }_{c}+x \ln a^{\prime \prime}{ }_{M}+(3-x) \ln a{ }_{\mathrm{Fe}}\right]
\end{aligned}
$$

where $a^{\prime}$ - is the activity of the components in austenite; $a^{\prime \prime}$ - is the activity of the components in cementite (standard state is pure component);

$N-$ is the atomic fractions of the components in austenite;

$x$ - is the fraction of the alloying element in the stoichiometric formula of cementite $\mathrm{Fe}_{3}{ }_{-x} \mathrm{M}_{x} \mathrm{C}$.

In alloyed austenite, carbon activity was found from the following relationships:

$$
\begin{gathered}
a_{c}^{\prime}=a_{c} \cdot f_{c^{n}} ; \\
a_{M}^{\prime}=\gamma_{M} N_{{ }_{M}}^{\prime} ; \\
a_{\mathrm{Fe}}^{\prime}=\gamma_{\mathrm{Fe}}\left(1-N_{c^{\prime}}-N_{{ }_{M}}^{\prime}\right)
\end{gathered}
$$

where $a_{c}$ - is the carbon activity in non-alloyed austenite; 
$f_{c}{ }^{m}$ - is the coefficient of influence of the alloying element on the carbon activity in austenite;

$\gamma_{m}$ - is the coefficient of activity of the alloying element in the austenite (conditionally accepted as independent from carbon content in the system);

$\gamma_{\mathrm{Fe}}$ - is the coefficient of ferrum activity in non-alloyed austenite.

The above thermodynamic characteristics of the elements in alloyed austenite are determined using the experimental data [4]:

$$
\begin{aligned}
& \ln f_{c^{M n}}=-4,15 N^{\prime}{ }_{M n} ; \ln f_{c} c^{c r}=17100 / T \\
& \gamma_{M n}=1,0 ; \gamma_{c r(1173-1273)}=2,82 \ldots 3,28 .
\end{aligned}
$$

Ferrum and carbon activities in alloyed austenite are:

$$
\begin{gathered}
\lg a_{c}=2105 / T-0,6735+\lg \left[N c /(1-5 N c)+0,9 N^{2} c\right] ;(8) \\
\lg a_{\mathrm{Fe}}=2,8653(1-N c)+0,2763 \cdot \lg (0,3819 N c)+1,3961 \times \\
\times \lg (0,5819-N c)+0,25 \cdot \lg (1-5 N c)-0,2117,
\end{gathered}
$$

where $\mathrm{Ne}-$ is the atomic fraction of carbon in austenite.

Based on the fact that in the two-phase equilibrium "austenite - cementite» system, the activity of each component in austenite is equal to its activity in cementite, the corresponding values of $a^{\prime \prime}$ were calculated using the same method as for $a^{\prime}$. Here, the initial $N c^{\prime}$ values for determining the values of $a^{\prime \prime}{ }_{c}$ (equal to the limit values of $a_{c}^{\prime}$ ) at specified temperatures were found on the line of ES pseudobinary 'ferrum - cementie' diagram taking into consideration the influence of manganese and chromium on this line [5].

The fraction $x$ of manganese or chromium in the alloyed cementite formula was determined by conodes method on the isotherm sections of ternary phase diagrams of Fe-Mn-C and Fe-Cr-C or by the coefficient of distribution of the alloying element between cementite and austenite, equal to 1.6 for $\mathrm{Mn}$ and 4.0 for $\mathrm{Cr}$.

Table 1 shows the results of the calculations of the free energy of the formation of carbides of cementite type in austenite alloyed with chromium and manganese.

As it can be seen from the above calculations, when chromium austenite is formed from alloyed cementite, the free energy of the system is reduced by a significantly greater value than when manganese austenite is formed. This distinction rapidly increases with the increase of the degree of steel alloying (Figure 1).

Thus, steel, alloyed with chromium, tends greater to form cementite in diffusion layers when it is saturated actively with carbon.

Table 1 - The free energy of the formation of carbides $\Delta G^{0}{ }_{\mathrm{Me} 3 \mathrm{C}}$ of austenite alloyed with manganese and chromium

\begin{tabular}{|l|l|l|l|l|l|l|l|}
\hline \multirow{2}{*}{$t,{ }^{\circ} \mathrm{C}$} & \multicolumn{6}{|l|}{$\Delta G^{0}$ MesC, J/g-at } \\
\cline { 2 - 8 } & $\begin{array}{l}\mathrm{Fe} \\
-\mathrm{C}\end{array}$ & $\begin{array}{l}1 \% \\
\text { at } \\
\mathrm{Mn}\end{array}$ & $\begin{array}{l}2 \% \\
\text { at } \\
\mathrm{Mn}\end{array}$ & $\begin{array}{l}3 \% \\
\text { at } \\
\mathrm{Mn}\end{array}$ & $\begin{array}{l}1 \% \\
\text { at } \\
\mathrm{Cr}\end{array}$ & $\begin{array}{l}2 \% \\
\text { at } \\
\mathrm{Cr}\end{array}$ & $\begin{array}{l}3 \% \\
\text { at } \\
\mathrm{Cr}\end{array}$ \\
\hline 900 & 330 & 1206 & 1805 & 2359 & 2635 & 4343 & 5719 \\
\hline 950 & 460 & 1392 & 2059 & 2665 & 2825 & 4527 & 5958 \\
\hline
\end{tabular}

Chromium in the composition of carburizing steel not only facilitates carbide formation, but also facilitates carbide precipitation in the form of isolated relatively equiaxial inclusions (Figure 2) which has a favourable impact on the kinetics of carburization process because carbon can diffuse relatively freely into the depth of the product in the sections of solid solution between cementite inclusions.

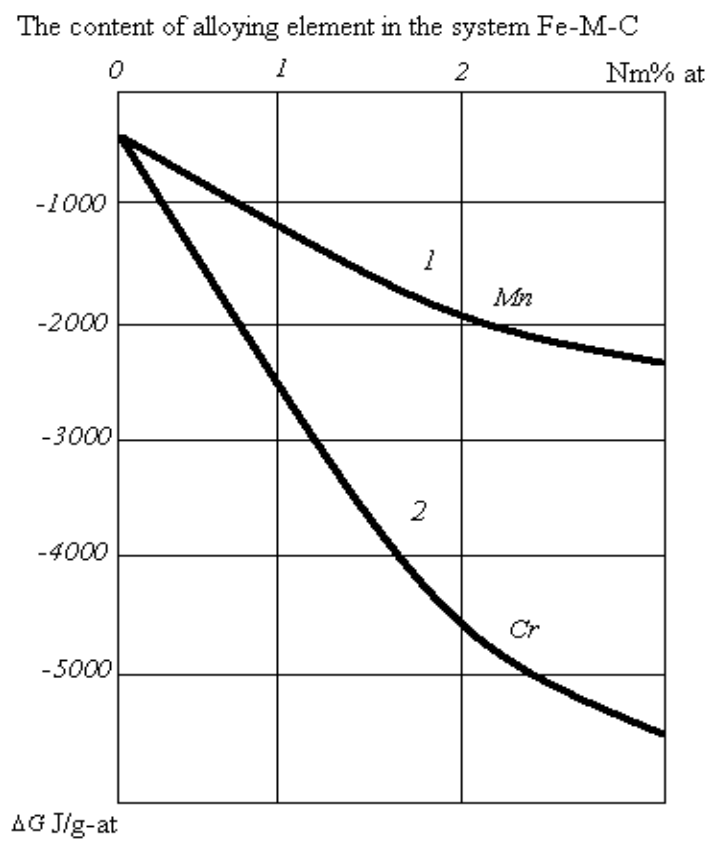

Fig. 1 - The dependence of free energy change in the system $\Delta G$ on the content of manganese (1) or chromium (2) $\mathrm{Nm}$ in it

The content of cementite in the diffusion layer of chromium steel $\left(\begin{array}{lllll}1.5 & \ldots & 3 \% & \mathrm{Cr}\end{array}\right)$ can reach $80 \ldots 90 \%$ which gives it an extremely high wear resistance.

The influence of manganese on carbide formation during cementation is very specific. Carburization of steels containing manganese leads to a marked increase in the carburizing parts size.

Carbide film is formed on the surface of the manganese steel by two substance flows opposite in direction carbon flow from a carburizing environment into metal and backflow of iron ions from solid-state solution into the reaction zone with carbon. This substance flow is called Stefan flow.

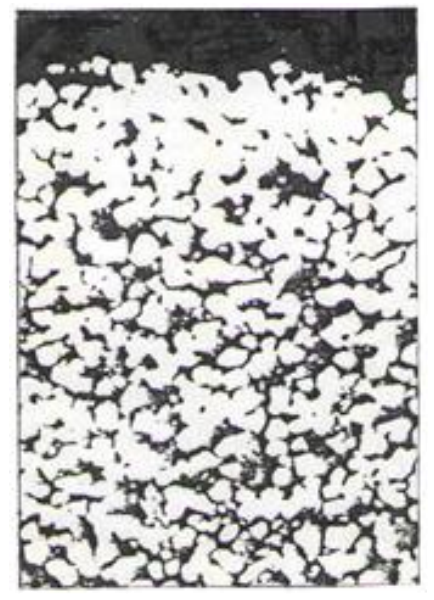

Fig. 2 - The microstructure of the diffusion alloy layer containing $2 \% \mathrm{Cr}$, carburized in the high activity cementation agent at $900{ }^{\circ} \mathrm{C}, 8 h \times 500$ 
It is considered that the diffusion of iron from the bottom of the product to its surface is activated by oxidative processes occurring during manganese steel cementation. Manganese has a high tendency to oxidation in comparison to iron and when oxygen comes from saturating medium (oxygen accompanies nitrogen diffusion), manganese actively reacts with it. In the presence of manganese, iron has a higher tendency to oxidation resulting in the formation of solid-state solutions of oxides $\mathrm{MnO}-\mathrm{FeO}$, so-called 'wustite' in the surface zone of the diffusion layer [6]. In the lattice of wustite there is high concentration of vacancies in the place of divalent iron ions, that is why the latter easily diffuse through the oxide layer to the surface forming a metal film. The system of equations of agent transfer in the layer of the reaction product with respect to Stefan flow includes the equations of continuity of mass and diffusion [7]:

$$
\begin{aligned}
& -\partial m / \partial t=\partial(m v) / \partial x \\
& -\partial m C / \partial t=\partial(j) / \partial x
\end{aligned}
$$

where $j$ is the total substance flow:

$$
j=(-D m \partial C / \partial x)+m v C .
$$

In equation (10), the first term characterizes the transfer of a substance by means of diffusion, the second one describes the transfer of a substance by means of mass flow. In equations (10)-(12):

$v$ is the translational rate of mass transfer in the layer;

$$
m=m_{1}+m_{2},
$$

where $m_{1}$ is the metal density (in the case under consideration it is austenite),

$m_{2}$ is the density of the reaction product (carbide);

$C$ is the relative (mean) weight concentration of carbon in the carbide layer;

$D$ is the - diffusion coefficient of carbon in the carbide film.

The initial condition $(t=0)$ is as follows: $x_{2}(0)=x_{1}(0)=x_{0}$, where $\mathrm{x}_{0}$ is the interface initial position, $x_{1}$ is the inner boundary layer of the reaction product (carbide film), $x_{2}$ is the outer boundary of this layer.

Boundary conditions $(t>0)$ are as follows: at the inner boundary $C=C_{1}$, on the outer boundary $C=C_{2}$, $C_{2}>C_{1}$

The solution of the system of equations (6)-(9) is as follows:

$$
x_{1}=2 \beta\left(D m_{2}^{2}\right)_{c=c 2} / m_{1}^{2} t ;
$$

$$
x_{2}=2\left[\left(\beta-\beta_{1}\right) \cdot\left(D m_{2}^{2}\right)_{c=c 2} / m_{2}^{2}+\beta_{1}\left(D m_{2}^{2}\right)_{c=c 2} / m_{2}^{2}-\right.
$$$$
\left.-\left(D m_{2}^{2}\right)_{c=c 2} / m_{1}^{2} t\right] \text {; }
$$

$$
\begin{aligned}
& \delta=x_{1}+x_{2}=2\left[\left(\beta-\beta_{1}\right) \cdot\left(D m_{2}{ }^{2}\right)_{c=c 2} / m_{2}{ }^{2}+\right. \\
& \left.+\beta_{1}\left(D m_{2}^{2}\right)_{c=c 1} / m_{2}^{2} t\right]
\end{aligned}
$$

where $\beta$ и $\beta_{1}$ are the parabolic law constants of the reaction product layer growth, they are subject to the calculation in each case. To determine constants $\beta$ and $\beta_{1}$ it is necessary to know the dependence of $\mathrm{Dm}_{2}{ }^{2}$ on $C$.

If we take into account that carbon relative weight concentration $(C)$ in the carbide film changes slightly (carbon is a lightweight element, iron is heavy), then as first approximation, we can assume that $D(C)=$ const,
$m^{2}(C)=$ const and the value $D m_{2}^{2}$ is constant. In this case, to calculate $\beta$ and $\beta_{1}$ the following equations can be used:

$$
\begin{gathered}
\left(\left(\beta-\beta_{1}\right) / \beta_{1}\right) \exp \left[\beta\left(\beta-2 \beta_{1}\right)\right]=C_{1} /\left(1-C_{2}\right) ; \\
\pi\left(\beta-\beta_{1}\right)\left[\operatorname{erf}\left(\beta-\beta_{1}\right)+\operatorname{erf} \beta_{1}\right] \exp \left[\left(\beta-\beta_{1}\right)^{2}\right]= \\
=\left(C_{2}-C_{1}\right) /\left(1-C_{2}\right)
\end{gathered}
$$

Constants $\beta$ and $\beta_{1}$ are calculated by substituting into equations (14) and (15) in the range of changes of the carbon relative weight concentration in carbide film, tentatively accepted equal to $C_{1}=0.067$ (corresponds to $\mathrm{Fe}_{3} \mathrm{C}$ ); $C_{2}=0.097-0.067$ (corresponds to carbides $\mathcal{E}$ - $\mathrm{Fe}_{2-3} \mathrm{C}$ ). The calculation results are presented in Table 2 , which shows that when the difference $C_{2}-C_{1}$ decreases, $\beta$, and $\beta_{1}$ markedly fall.

Table 2 - The dependence of constants $\beta$ и $\beta_{1}$ in equations (16), (17) and the thickness of carbide film $\delta$ on $\Delta C=C_{2}-C_{1}$ $\left(C_{1}=0,067 ; D=8,6-10^{-12} \mathrm{sm}^{2} / \mathrm{s}\right)$

\begin{tabular}{|l|l|l|l|l|l|l|}
\hline$C_{2}$ & $\Delta C$ & $\beta$ & $\beta_{1}$ & $\begin{array}{l}\delta=x_{1}+x_{2}, \\
\text { мкм }\end{array}$ & $x_{1}$ & $x_{2}$ \\
\hline 0.097 & 0.030 & 0.464 & 0.426 & 4.0 & 3.2 & 0.8 \\
\hline 0.090 & 0.023 & 0.407 & 0.375 & 3.5 & 2.8 & 0.7 \\
\hline 0.082 & 0.015 & 0.337 & 0.311 & 2.9 & 2.3 & 0.6 \\
\hline 0.075 & 0.008 & 0.241 & 0.224 & 2.1 & 1.6 & 0.5 \\
\hline
\end{tabular}

As at a first approximation it was assumed that $D(C)$ and $m_{2}(C)$ are constant, the value of $D$ is calculated by equation (15) using the experimental value of $\delta$ and calculated values of $\beta$ and $\beta$. The resulting dependence of specified characteristics on $\Delta C$ is shown in Fig. 3, which shows that the use of equations (13) - (17) allows taking into account the role of Stefan flow in the formation and growth of carbide film on steel in the process of its carburization. The calculation allowed roughly assess the transport of both inner and outer film boundaries.

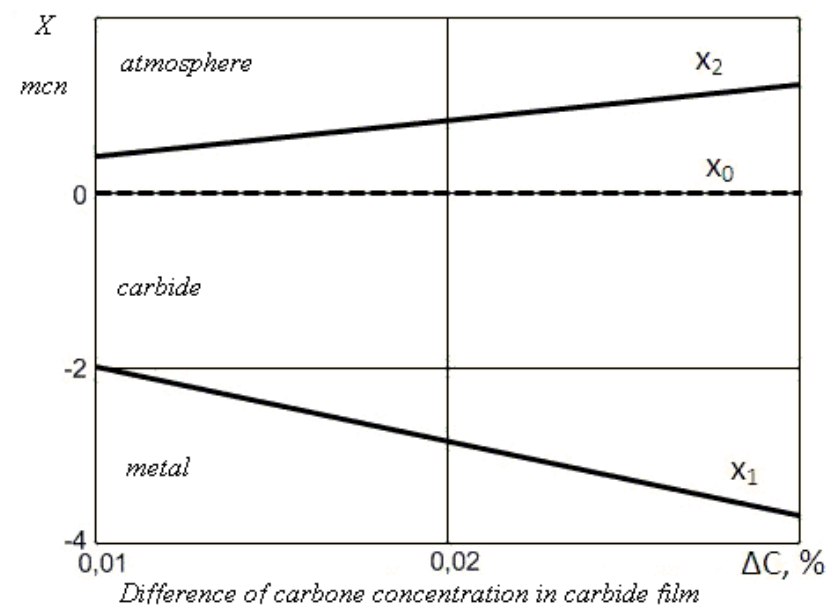

Fig. 3 - The dependence of the position of inner $\left(x_{1}\right)$ and outer $\left(x_{2}\right)$ boundaries of carbide film on the difference of carbon concentrations from outer and inner sides

It can be concluded from the calculated and experimental data that a carbide film formed when carburizing manganese steel was uneven in thickness. Its thickness varies from 1 to 5 microns even at a thin section, although the content of manganese in steel (within certain 
limits) has little effect on the thickness of the carbide film on the surface (Fig. 4).

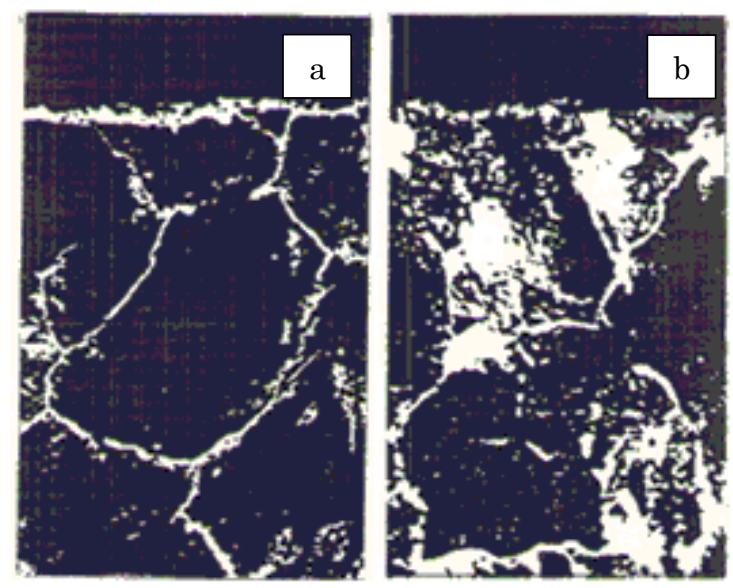

Fig. 4 - The microstructures of the carbonized steel samples at $900{ }^{\circ} \mathrm{C}, 8 h \times 500: \mathrm{a}-1 \% \mathrm{Mn} ; \mathrm{b}-3 \% \mathrm{Mn}$

\section{REFERENCES}

1. S. Pakrasi, Harter-Techn. Mitt. A 43 No 6, 365 (1988).

2. L.I. Roslyakova, I.N. Roslyakov, J. Nano-Electron. Phys. 6 No 3, 03047 (2014).

3. Ю.М. Лахтин, Металловедение и термическал обработка металлов № 7, 6 (1993) (Yu.M. Lakhtin, Metallovedeniye i termicheskaya obrabotka metallov No 7, 6 (1993)).

4. I.N. Roslyakov, L.I. Roslyakova, D.V. Kolmikov, Mechan.
When cementite precipitates from austenite, first, an intermediate hexagonal environment (metastable carbide or specific carbide condition) $\mathcal{\varepsilon}-\mathrm{Fe}_{2-3} \mathrm{C}$ is formed; it has a wide homogeneity range. In other words, unlike the stable carbide $\varepsilon$-phase can exist with different carbon content. The uneven growth of carbide skin is explained, apparently, by the unevenness of a homogeneous region of carbide $\varepsilon$-Fe2-3 $\mathrm{C}$ in different parts of the surface which, in turn, is due to the possible unevenness of the distribution of oxides under neath.

\section{CONCLUSION}

Thus, it can be concluded that chromium is present in the carburized steel stabilizes substantially cementite, facilitating its precipitation during steel carburization in the form of separate inclusions in the diffusion layer. Manganese stabilizes cementite much weaker than chromium, though facilitates carbide formation in the sense that it forms an intermediate $\varepsilon$-phase, through which carbon diffusion is possible.

Eng. No 3, 62 (2011).

5. D. Liedtke, Maschinenbau A10 No 5, 35 (1981).

6. М.Г. Крукович, Металловедение и термическая обработка металлов № 1, 24 (2004) (M.G. Krukovich, Metallovedeniye $i$ termicheskaya obrabotka metallov No 1,24 (2004)).

7. R. Zenker, U. Zenker, Surf. Eng. 29 No 1, 45 (1989). 